\title{
Integrating Nanomaterial and High-Performance Fuzzy-Based Machine Learning Approach for Green Energy Conversion
}

\author{
A. V. L. N. Sujith, ${ }^{1}$ R. Swathi, ${ }^{2}$ R. Venkatasubramanian, ${ }^{3}$ Nookala Venu, ${ }^{4}$ S. Hemalatha, ${ }^{5}$

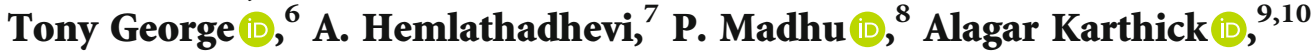 \\ M. Muhibbullah $\mathbb{D},^{11}$ and Sameh M. Osman ${ }^{12}$ \\ ${ }^{1}$ Department of Computer Science and Engineering, Anantha Lakshmi Institute of Technology and Sciences, Ananthapuramu, \\ Andhra Pradesh-515721, India \\ ${ }^{2}$ Department of Computer Science and Engineering, Sri Venkateswara College of Engineering, Tirupati, \\ Andhra Pradesh-517502, India \\ ${ }^{3}$ Department of Electrical and Electronics Engineering, New Prince Shri Bhavani College of Engineering and Technology, Chennai, \\ Tamil Nadu- 600073, India \\ ${ }^{4}$ Department of Electronics and Communication Engineering, Balaji Institute of Technology and Science, Narsampet, Warangal, \\ Telangana-506331, India \\ ${ }^{5}$ Department of Computer Science and Engineering, Panimalar Institute of Technology, Chennai, Tamil Nadu-600123, India \\ ${ }^{6}$ Department of Electrical and Electronics Engineering, Adi Shankara Institute of Engineering and Technology, Mattoor, Kalady, \\ Kerala-683574, India \\ ${ }^{7}$ Department of Computer Science and Engineering, Panimalar Engineering College, Chennai-600123 Tamil Nadu-600123, India \\ ${ }^{8}$ Department of Mechanical Engineering, Karpagam College of Engineering, Coimbatore, Tamil Nadu-641032, India \\ ${ }^{9}$ Renewable Energy Lab, Department of Electrical and Electronics Engineering, KPR Institute of Engineering and Technology, \\ Coimbatore 641407, Tamil Nadu, India \\ ${ }^{10}$ Departamento de Quimica Organica, Universidad de Cordoba, EdificioMarie Curie (C-3), Ctra Nnal IV-A, Km 396, \\ E14014 Cordoba, Spain \\ ${ }^{11}$ Department of Electrical and Electronic Engineering, Bangladesh University, Dhaka 1207, Bangladesh \\ ${ }^{12}$ Chemistry Department, College of Science, King Saud University, P.O. Box 2455, Riyadh 11451, Saudi Arabia
}

Correspondence should be addressed to M. Muhibbullah; m.muhibbullah@bu.edu.bd

Received 16 November 2021; Accepted 13 December 2021; Published 29 January 2022

Academic Editor: Awais Ahmed

Copyright $\odot 2022$ A. V. L. N. Sujith et al. This is an open access article distributed under the Creative Commons Attribution License, which permits unrestricted use, distribution, and reproduction in any medium, provided the original work is properly cited.

\footnotetext{
Biomass is a renewable and sustainable green energy material. It is made up of lignin, cellulose, and hemicellulose with considerable amount of water, extractives, and inorganic chemical compounds. The use of biomass materials and other biogenic wastes for energy recovery represents an eco-friendly way. Biomass material selection is one of the most significant aspects for any energy conversion process, and it is a common outsourcing problem that includes material preparation, reactor performance, economic assessment, and calorific value of the products. Fuzzy systems can be quite useful in high-performance computing during the selection of biomass materials. In each engineering process, material selection is a crucial step since each material is having its own set of characteristics. This study presents the application of type-1 fuzzy set for the selection of suitable biomass material for yielding maximum bio-oil. This study focuses on seven locally available materials such as rice straw (M-1), sunflower shell (M-2), hardwood (M-3), wheat straw (M-4), sugarcane bagasse (M-5), corn cop (M-6), and palm shell (M-7). The study evaluated seven important properties of the materials such as lignin (P-1), cellulose (P-2), hemicellulose $(\mathrm{P}-3)$, volatile matter (P-4), fixed carbon (P-5), moisture content (P-6), and ash content (P-7). The findings demonstrated that sugarcane bagasse (M-5) is the best option for maximum bio-oil yield. Furthermore, the potential of nanoscale catalysts in improving the yield of bio-oil through real-time experiments was studied. The findings of this work add to our understanding of the application of fuzzy-based systems for energy applications.
} 


\section{Introduction}

In recent years, the use of biomass materials for the production of valuable chemicals and biofuels has gained popularity as a way to minimise emissions of greenhouse gases emitted by the combustion of fossil diesel fuels [1]. It is an organic substance with a lot of chemical energy. It has traditionally been used for energy purposes through direct burning. The annual global biomass production is expected to be 146 billion metric tonnes. The current biomass availability in India is estimated as $\mathbf{5 0 0}$ million metric tonnes per year. According to the report received from ministry, biomass availability is expected to be between 120 and 150 million metric tonnes per year. Biomass presently accounts for $32 \%$ of the country's overall primary energy consumption. It is a renewable resource that appears to offer clear environmental benefits and lower greenhouse gas emissions. Wood chips and agricultural wastes are the examples for low-value biomass feedstocks. It comprises a wide range of chemical components. Alcohols [2], organic acids [3], formic acid, and furfurals [4] are among the compounds addressed. These chemicals are then transformed into a variety of derivatives that are employed in the chemical and pharmaceutical sectors. Many researchers have published data on chemicals extracted from a wide range of biomass feedstocks, as well as specific feedstocks including carbohydrates, triglycerides, cellulose, hemicellulose, lignin [5], and furfural [6]. Machine learning algorithms are designed to extract knowledge from data using classic approaches such as clustering, classification, and relationships. To create more flexible outcomes, fuzzy sets are used in combination with these approaches. In the construction of machine learning algorithms and models, fuzzy-based knowledge representation and reasoning are widely used. They gave a new-fangled life to the scientific truth of machine learning which have been in a hidden stage for a long period. Fuzzy sets are used throughout the data processing stage because it may simulate partial and inaccurate data representations. In the mapping of data representation, the fuzzy extension principle was used.

The effective handling of erroneous data and uncertainty is a critical phenomenon in any decision-making process. According to Lee et al. [7], if the imprecision of humanity's decision-making process is mishandled, the results could be perplexing. Fuzzy set theory is a wonderful tool for expressing human knowledge [8]. It is a formalised technique for scientifically conveying ambiguity and vagueness [9]. Zadeh proposed fuzzy sets theory in 1965 as an expansion of the classical notion of set [10]. Salii defined an L-relation, a more broad type of structure that he examined in an abstract algebraic framework [11]. Fuzzy relations are a type of fuzzy relation that is currently widely used in fuzzy mathematics and has applications in linguistics, decision-making, and clustering. Fuzzy set theory has been used by several researchers to deal with uncertainty in a range of decisionmaking problems [12]. Many literatures used fuzzy-based techniques for energy management system. Previously, Chehri and Mouftah [13] proposed this system for hybrid grid solar power energy management system. Samuel [14] proposed a home energy management system based on a multioutput adaptive neurofuzzy inference system. For a photovoltaic solar home, Chekired et al. [15] proposed a fuzzy logic energy management system. The main idea behind this study is to evaluate the biomass materials in order to get higher quantity and rich biofuel by evaluating the yield parameters. This can be attained with the aid of fuzzy logic and fuzzy inference systems, which have been shown to be useful tools. This system can identify, predict, and control the complex, nonlinear, and imprecise systems. This is very attractive technology that can solve any problems without any accurate mathematical models [16]. Typically, a fuzzy system is formed by collecting knowledge from subject experts and converting their tacit knowledge of the underlying process into linguistic variables and fuzzy rules. Previously, this approach was used for various decision-making processes such as identification of suitable distributor location [17], medicine [18], assessment of power transformer [19], employee performance [20], and hospital performance [21].

Pyrolysis is the method of thermochemical decomposition of organic compounds for the production of energyrich biofuel in the absence of air at elevated temperatures. There are three different types of pyrolysis reactions differentiated based on the process temperature and reaction time. They are conventional slow pyrolysis, fast pyrolysis, and flash pyrolysis. In fast and flash pyrolysis, the biomass is heated rapidly up to the temperature of $500^{\circ} \mathrm{C}$ to $650^{\circ} \mathrm{C}$. Among other thermochemical conversion processes, pyrolysis offers an innovative solution to problems with heat transmission, product quantity, and quality. In the point of environment considerations particularly emission and waste management, pyrolysis technologies for biomass conversion to energy generation have attracted more attention in recent years and are increasingly attaining advances [22]. Furthermore, for the pyrolysis reactors for biomass conversion into bio-oil, char gas offers various advantages, including improved product quality, reduced operating costs, higher liquid product yield, enhanced reaction speeds, and lower heat requirements. Catalytic pyrolysis is a potential technology for improving biomass-based materials into liquid fuel and other value-added products [23]. Use of nanobased catalysts enhances the pyrolysis process with lower activation energy by lowering the lowering pyrolysis temperature [24]. In catalytic process, the catalyst and feedstock materials are mixed together and kept inside the reactor for catalytic reforming and cracking. Various types of catalysts including nickel-based, metal-based, alkalibased, zeolite catalysts, and carbon-supported catalysts are used in various processes for the production of higher amount of volatiles [25]. For the catalytic pyrolysis conversion of wood-based biomass materials, ZSM- 5 zeolite is the most commonly utilized catalysts. Because of the medium pore size and two-dimensional channel-like pore structure, these catalysts are widely used for increasing maximum fuel yield from biomass [26]. The ambient environment had a substantial impact on the catalytic pyrolysis effects particularly which could boost hydrogenation by increasing catalyst accessibility. The identification of suitable material for the yielding maximum biofuels and chemicals has not been 
examined using analytical hierarchy process (AHP) and other multicriteria decision-making (MCDM) approaches.

This research focused on the use of fuzzy AHP to select suitable biomass materials for thermochemical conversion processes, specifically pyrolysis. Pyrolysis is a hopeful option for thermochemical conversion of lignocellulosic material. It is a method for converting organic molecules into energyrich products. This method can produce carbon as a byproduct, which is referred to as carbonization. Pyrolysis, unlike other high-temperature processes such as hydrolysis and combustion, does not require the use of water, oxygen, or other reagents. It is a simple, inexpensive technology that can be used for variety of feedstocks. This process produces high-quality liquid oil and chemicals when compared to other conversion techniques. The qualities and requirements for selecting the best biomass material are examined using expert critiques and literature before selecting numerous materials for this study. The selected materials are available plenty and have no value. After the cultivation, these materials are burnt in open atmosphere in the field itself because of its low density. Open burning of these materials causes severe impact on the environment. So appropriate recycling of these materials is essential. In this context, this study selected seven alternatives out of available plenty in nature to produce maximum liquid oil through thermal and nanocatalytic pyrolysis by investigating its lignocellulosic and its components identified through proximate analysis. The developed fuzzy logic model predicted the yield for a given set of inputs. Finally, the prediction is validated with experimental study conducted by using specified set of input through thermal as well as catalytic pyrolysis.

\section{Materials and Methodology}

2.1. Materials. The raw biomass materials used for this study are collected from local agricultural field in Coimbatore, India. The raw wood is finely processed into particles having average diameter of less than $0.5 \mathrm{~mm}$. For this form, the biomass materials are initially processed with ball mill and shieved using shieve shaker. To promote pyrolysis reaction and feedstock characterization, the particle size of the biomass materials is very important to prevent heat and mass transmission constraints. So the feedstock has been ground to below $0.5 \mathrm{~mm}$. Before evaluating proper characteristic study, the biomass materials are dried in open sunlight for a week and further dried in an oven for $1 \mathrm{hr}$ maintained at $\pm 100^{\circ} \mathrm{C}$. This process can considerably remove the moisture content in the biomass samples which affect the process as well as yield quantity.

\subsection{Methods}

2.2.1. Material Evaluation. Economic and environmental variables are the two most important elements that can influence biomass material choices. They are listed as follows. Various studies explain some parameters to consider in biomass selection. However, no study effectively specifies this information. Figure 1 shows the property evaluation of the biomass materials.

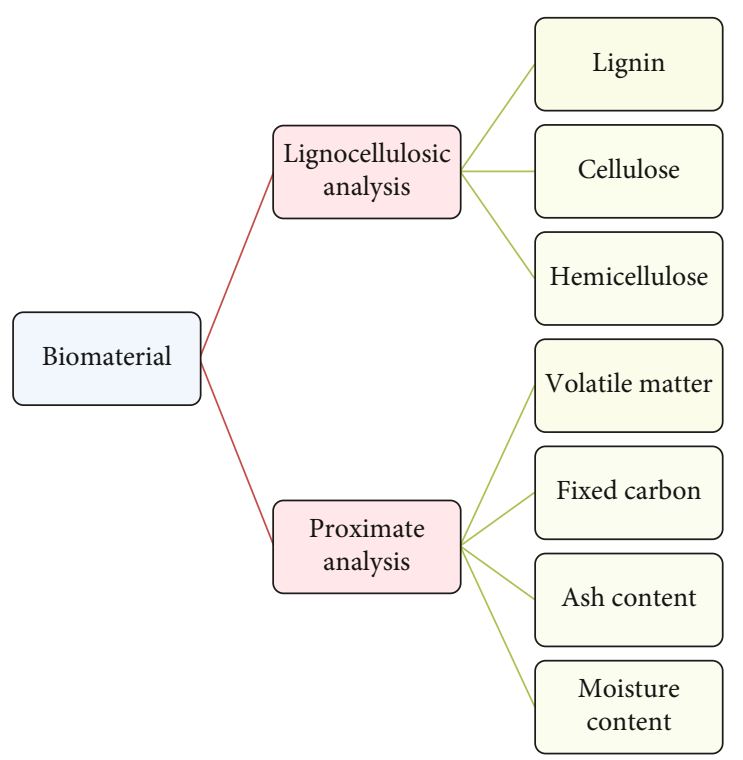

FIgURE 1: Biomass material property evaluation.

(i) Input. Cost for production and storage

(ii) Output. Yield of biofuel

(iii) Conversion Rate. Efficiency of conversion

(iv) Emission. Release of harmful gases

(v) Usage of Chemicals. Properties of chemicals obtained from product

(vi) Technological Development. Gap between current stages

(vii) Sustainable Energy. Replacing fossil fuel

2.2.2. Type-1 Fuzzy Approach. Fuzzy sets were brought out by Zadeh in 1965 as the expansion of the conventional notion of set [10]. Here, each constituent has depicted with the help of membership function valued in the actual unit interval $[0,1]$. Because of their ability to handle vagueness in preference values, fuzzy set theory has steadily gained favour in the selection of appropriate materials. This approach is frequently utilized in a variety of fields when data is partial or inaccurate [27]. The type-1 fuzzy set $\tilde{a}$ in $X$ is a set of well-organized pair where $\tilde{a}$ is represented as $\tilde{a}=\left\{\left(x, \mu_{\tilde{a}}(x)\right) \mid x \in X\right\}$ where $x$ represents the constituents of the set $X$ and $\mu_{\tilde{a}}(x)$ is called the membership function or the degree of membership of $x$.

Suppose $\tilde{a}$ is a triangular fuzzy number (TFN) $\left(a_{l}, a_{m}, a_{u}\right)$, where $a_{l}, a_{m}$, and $a_{u}$ are the promising values of membership function shown in Figure 2.

Then the membership function is defined as

$$
\mu_{\tilde{a}}(x)=\left\{\begin{array}{l}
1-\frac{a_{m}-x}{a_{m}-a_{l}}, a_{l} \leq x \leq a_{m}, \\
1-\frac{x-a_{m}}{a_{u}-a_{m}}, a_{m} \leq x \leq a_{u}, \\
0, \text { otherwise. }
\end{array}\right.
$$




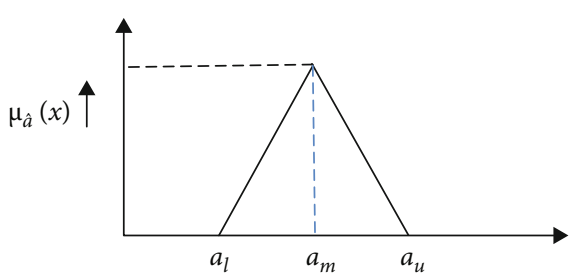

FIgURE 2: Illustration of triangular fuzzy set.

Suppose $\tilde{a}=\left(a_{l}, a_{m}, a_{u}\right)$ and $\tilde{b}=\left(b_{l}, b_{m}, b_{u}\right)$ are two triangular fuzzy numbers so the mathematics operations between two type-1 fuzzy sets are as follows:

$$
\begin{gathered}
\tilde{a} \oplus \tilde{b}=\left(a_{l}+b_{l}, a_{m}+b_{m}, a_{u}+b_{u}\right), \\
\tilde{a} \ominus \tilde{b}=\left(a_{l}-b_{l}, a_{m}-b_{m}, a_{u}-b_{u}\right), \\
\tilde{a} \otimes \tilde{b}=\left(a_{l} \times b_{l}, a_{m} \times b_{m}, a_{u} \times b_{u}\right), \\
\tilde{a} \\
\overline{\tilde{b}}=\left(\frac{a_{l}}{b_{u}}, \frac{a_{m}}{b_{m}}, \frac{a_{u}}{b_{l}}\right), \\
\frac{1}{\tilde{b}}=\left(\frac{1}{b_{u}}, \frac{1}{b_{m}}, \frac{1}{b_{l}}\right), \\
k \times \tilde{b}=\left(k \times b_{l}, k \times b_{m}, k \times b_{u}\right),
\end{gathered}
$$

where $k$ is a crisp number.

The choice of material for thermochemical conversion to produce biofuels and chemicals is a strategic and critical decision for researchers. The evaluation of many parameters is part of this selecting procedure. This approach involves evaluating a number of factors to select the best biomass source. Some studies may consider higher profits and better outcomes; however, the evaluation should be focused on social and environmental issues. The majority of researchers are only interested in the biological composition of biomass. For 2nd-era ethanol, Kahr et al. [28] evaluated the lignocellulosic ethanol potential of wheat straw, rice straw, oat straw, and maize stover among other potential agricultural wastes. Ciancolini et al. [29] used agglomerative hierarchical cluster analysis to assess the biomass and polyphenol production of eight cardoon genotypes. Nine capacities are tested in this study in order to find significant differences. Vaezi et al. [30] developed a numerical set of rules for biomass material selection in the gasification process. Figure 3 shows the methodology adopted for this study.

\subsubsection{Validation by Catalytic Pyrolysis Experiment}

(1) Reactor Setup. The pyrolysis reactor is the heart of the pyrolysis process. In this study, the top two ranked biomass material suggested by fuzzy technique is utilized for fixedbed pyrolysis in order to verify the reliability of the assessment. For this purpose, the reactor made up of stainless steel with inner diameter $100 \mathrm{~mm}$ and length $150 \mathrm{~mm}$ is utilized. The system consists of heating system, condenser unit, and liquid collection system. The reactor is heated with a $2 \mathrm{~kW}$ electrical resistance heater attached with ammeter and volt- meter setup. A separate autotransformer is attached with the reactor to control the rate of heat input. For proper collection of bio-oil, the evolved gas generated from the reactor is allowed through the condenser, in which the ice water maintained at $0^{\circ} \mathrm{C}$ is supplied for the condensation process. The condensed liquid oil is then collected into the glass beaker and stored for further study. The char generated during the pyrolysis process was collected from the bed directly at the end of each run. The uncondensable gases produced from the reactor are collected by using gas balloon system.

(2) Reaction Process. ZSM-5 is selected for this study due to its higher activity and stability, as well as its good selectivity, metal tolerance, and flexibility, especially when used as an additional catalyst [31]. Zeolites can be shape-selective catalysts through transition state selectivity or molecular diameter-based exclusion of competing reactants. These catalysts can be utilized for oxidation. The processes can take place within the pores of the zeolite. Desilication of ZSM-5 with $\mathrm{NaOH}$ solution produced HZSM-5 for the catalytic process. For this, 25 grams of zeolite is combined with a $250 \mathrm{~mL}$ of $0.3 \mathrm{M} \mathrm{NaOH}$ and maintained at $75^{\circ} \mathrm{C}$. After that, the mixture is filtered and dried in an oven by keeping the temperature not less than $100^{\circ} \mathrm{C}$. The dried sample was changed to hydronium form with a $0.2 \mathrm{M} \mathrm{NH}_{4} \mathrm{NO}_{3}$ solution at $80^{\circ} \mathrm{C}$ for 24 hours and then again dried at $100^{\circ} \mathrm{C}$ and calcined at $500^{\circ} \mathrm{C}$ for almost 6 hours, yielding 0.3 HZSM- 5 as the final product. On the reactor, 100 grams of powdered biomass was combined with catalyst and reaction was carried out at by keeping the bed temperature of $500^{\circ} \mathrm{C}$. The evolved gases coming out from the reactor are allowed to condenser unit, and the condensed vapour is collected in the form of bio-oil. The weight of the bio-oil is measured directly with the help of weighing machine. Each experiment is conducted till no volatile matter is released from the reactor. For that purpose, minimum of $45 \mathrm{~min}$ is maintained for each run. In catalytic pyrolysis process, two types of reactions are taken place inside the reactor. First is the formation of phenolic contents due to deoxygenation or the loss of one or two oxygen atoms. This stage is also the responsible for the formation of cyclopentadiene, fulvenone, and fulvene components. The process of deoxygenation is basically driven by the stability of the separation groups such as water, carbon monoxide, and carbon dioxide. Second is the formation of final products and transmethylation. This stage is responsible for the production of cresols and methyl components [32]. The yield of the desired product is found by the following formula.

$$
\text { Yield }(\text { wt } \%)=\frac{\text { Yield of oil } / \text { char } / \text { gas }}{\text { Biomass feed }} .
$$

\section{Results and Discussion}

3.1. Material Selection. Biomass material selection is mainly concerned with the biomass to biofuel conversion techniques in order to yield the maximum biofuels such as crude bio-oil, char, and gas to fulfil the future energy needs. In the world, there are plenty of materials available as a resource 


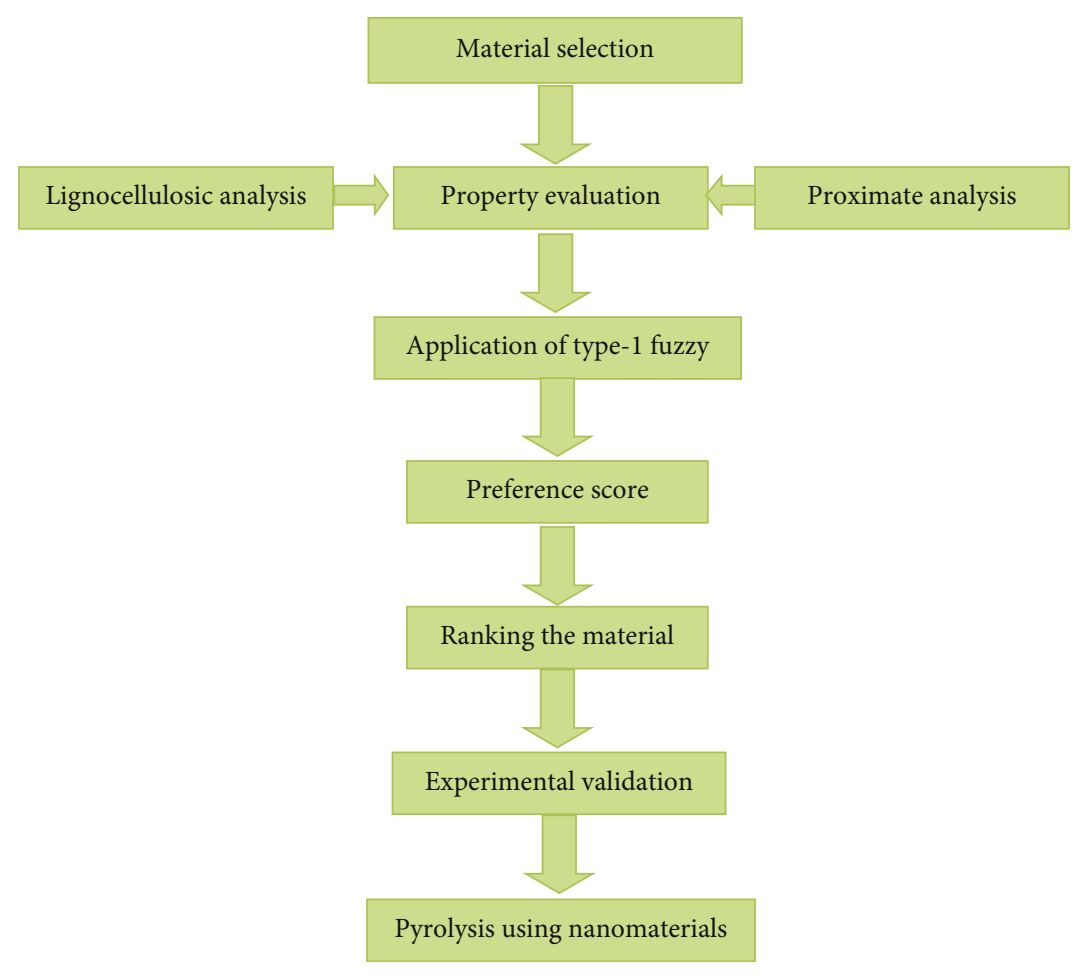

FIGURE 3: Methodology.

for various applications. Each material has its own unique characteristics, applications, advantages, and limitations. Earlier than the beginning of petro oil era, renewable feedstock materials were a major segment for total energy and chemical supplies. Biomass is a natural material supply chemicals and energy up to date. Among the other types of renewable materials, lignocellulosic biomass are available abundant, low-value materials utilized for fuels, chemicals, and energy to replace fossil resources [33]. They are composite material which has cellulose, hemicellulose, and lignin approximately at $50 \mathrm{wt} \%, 25 \mathrm{wt} \%$, and $25 \mathrm{wt} \%$, respectively [34]. The components are connected mutually to provide structural stability. It also contains reasonable amount of water, extractives with inorganic elements. Cellulose is a linear long-chain polymer that encircles mostly crystalline structures with tiny amorphous regions. They are structured in fibrils and then grouped together to form cellulose fibres, which are aware of the fibrous character of biomass cell walls. Hemicelluloses are also the amorphous polymers having shorter structure of five to six carbon sugars. It serves as a link between the cellulose and the lignin [35]. Lignin is a three-dimensional polymer made up of phenylpropane units linked together in a number of ways. The most prevalent outsourcing difficulty is material selection, which is the most important aspects of any biomass conversion process. Since different materials have some unique properties and value, the procedure for biomass material selection has a main role related to the conversion efficiency as well as the heating value of the biofuel [36]. This process of selection is identified to be the imperative decision-making process for biofuel conversion techniques which includes biomass preparation, performance of the reactor, economic evaluation, and heating value of the biofuel products.

3.2. Evaluation of the Material Properties. Different biomass materials have some unique characteristics. Analysis of material properties shown in Figures 4-10 is very important for the selection of best biomass material for pyrolysis. Chemical analysis biomass material is one of the most essential parts during the evaluation of reaction characteristics. In biomass, cellulose and lignin are often considered as the most important components [37]. The lignocellulosic content of materials is measured using the conventional wet chemistry technique. It is suggested as the best approach for analysis of lignocellulosic contents [38]. This method is a powerful and accurate method, whereas 0.50 grams of samples is analysed for each entry. Figure 4 shows the lignin content, and Figure 5 shows the cellulose content present in the materials 1 to 7 . According to the data, the lignin content of the materials is varied from $13.4 \mathrm{wt} \%$ to $44 \mathrm{wt} \%$. It can be clearly shown that M-5 has lower lignin content but M-7 has higher lignin concentrations. Generally, higher lignin contents of the material slower the pyrolysis reaction yielding maximum char. The presence of cellulose in the material enhances the thermochemical conversion yielding maximum liquid products [39]. The values of cellulose in the selected materials vary from $27.7 \mathrm{wt} \%$ to $52.5 \mathrm{wt} \%$. The material M-6 contains the highest amount of cellulose content of all the samples, and M-7 has the lowest. With reference to lignin and cellulose contents, M-6 may be suggested as a suitable material, but the hemicellulose content of the material M-6 is lower than the M-2 and M-5. 


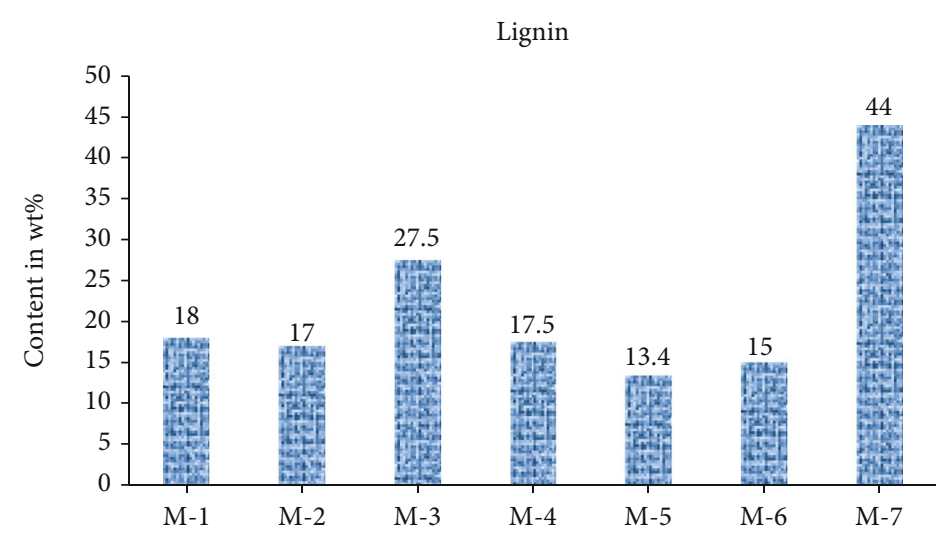

Figure 4: Lignin contents of the selected materials.

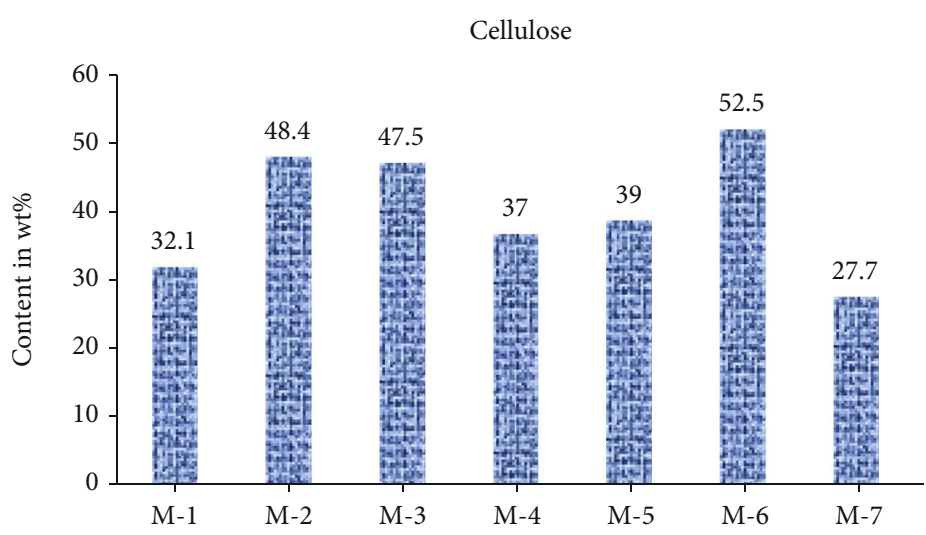

FIGURE 5: Cellulose contents of the selected materials.

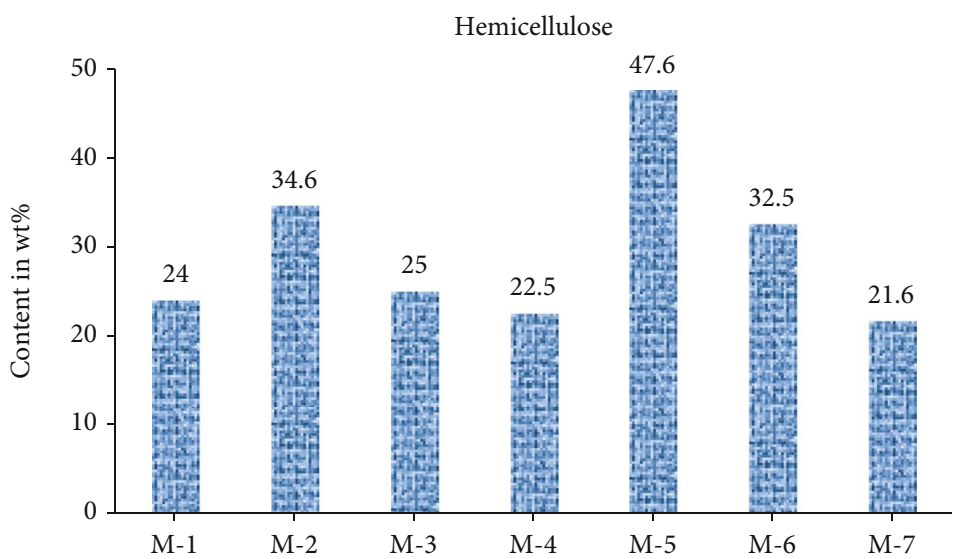

Figure 6: Hemicellulose contents of the selected material.

The presence of hemicellulose content of the material also enhances the conversion of material to biofuel during pyrolysis. The total content of the cellulose and hemicellulose is termed as holocellulose favour for the yield of biofuel. Based on the above said three properties, the favourable material for yielding maximum biofuel cannot be suggested without deep investigation. Material with more volatile contents produces more bio-oil and biogas, while material with higher fixed carbon yields more char particles. The selected sample is having more amount of volatile contents $(58.8 \mathrm{wt} \%$ to
$80.2 \mathrm{wt} \%)$. Based on volatile contents, M-5 can be suggested as the best one for maximum energy conversion. The presence of fixed carbon in the material is ranging from $6.54 \mathrm{wt} \%(\mathrm{M}-6)$ to $21.0 \mathrm{wt} \%(\mathrm{M}-4)$. The material's moisture content has an impact on the heat transfer phenomena during energy conversion [40]. The moisture content present in the feedstock might obviously reduce the reaction temperature. During conversion process, the initial heat applied to the process is used to evaporate the moisture content of the feedstock material. It also affects the heating value of 


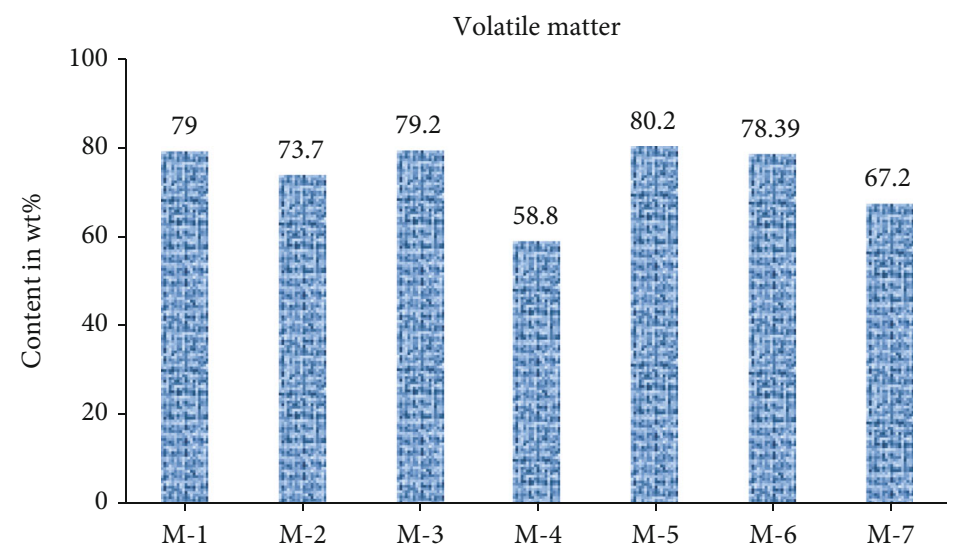

Figure 7: Volatile matters of the selected materials.

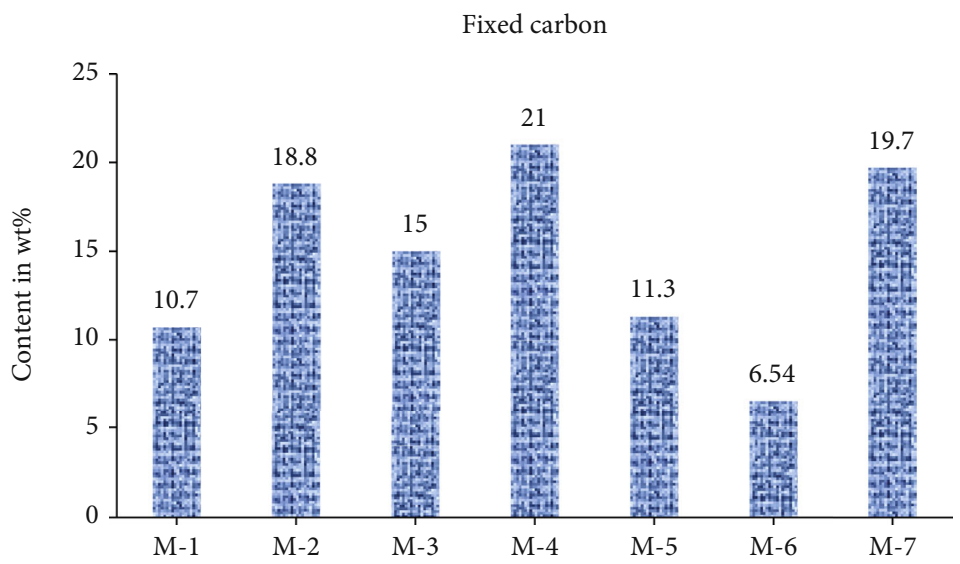

Figure 8: Fixed carbons of the selected materials.

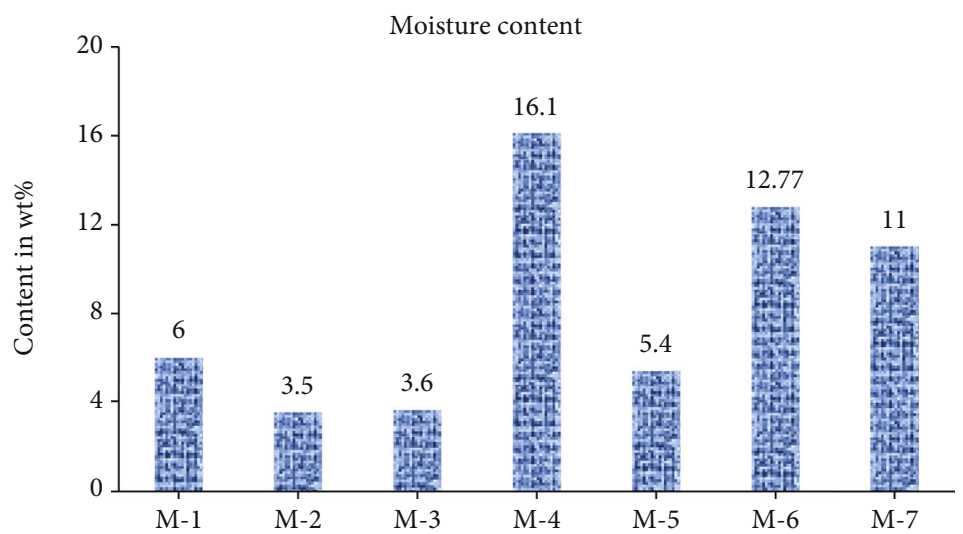

Figure 9: Moisture contents of the selected materials.

the reaction products. Previously, many studies have recommended the feed particles should have lower moisture content in order to favour for quality bio-oil yield [41, 42]. The material with lower moisture content always yields the fuel with higher energy content [43]. According to Figure 9, the moisture content of the materials is varied from $3.5 \mathrm{wt} \%$ to $16.1 \mathrm{wt} \%$. From the figure, it can be shown that M-2 has lower moisture content whereas M-4 has more. The analysis was carried out in accordance with ASTM pro- cedures to determine the proximate analysis (VM-ASTM D3175, FC-By difference, MC-ASTM D3173, and ACASTM D3174). The increased moisture content in the material significantly affects the oil quality. The influence of ash content during pyrolysis has been studied extensively. The amount of ash in the biomass sample has a direct impact on the yield and composition of the pyrolysis products. It also has an impact on the efficiency of the conversion process. As a result, one of the factors for selecting the best 


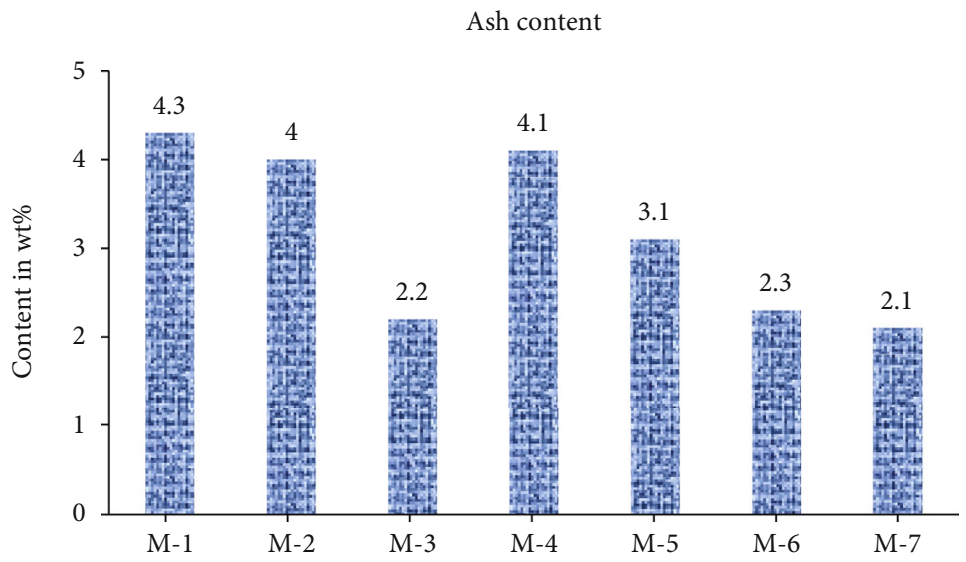

Figure 10: Ash contents of the selected materials.

TABLE 1: Type-1 fuzzy pairwise comparison matrix for weight calculation.

\begin{tabular}{lccccccc}
\hline & P-1 & P-2 & P-3 & P-4 & P-5 & P-6 & P-7 \\
\hline P-1 & $(1,1,1)$ & $\left(\frac{1}{5}, \frac{1}{4}, \frac{1}{3}\right)$ & $\left(\frac{1}{3}, \frac{1}{2}, \frac{1}{1}\right)$ & $\left(\frac{1}{7}, \frac{1}{6}, \frac{1}{5}\right)$ & $\left(\frac{1}{3}, \frac{1}{2}, \frac{1}{1}\right)$ & $(1,2,3)$ & $\left(\frac{1}{3}, \frac{1}{2}, \frac{1}{1}\right)$ \\
P-2 & $(3,4,5)$ & $(1,1,1)$ & $(1,2,3)$ & $\left(\frac{1}{3}, \frac{1}{2}, \frac{1}{1}\right)$ & $(2,3,4)$ & $(2,3,4)$ & $(1,2,3)$ \\
P-3 & $(1,2,3 ; 1)$, & $\left(\frac{1}{3}, \frac{1}{2}, \frac{1}{1}\right)$ & $(1,1,1)$ & $\left(\frac{1}{4}, \frac{1}{3}, \frac{1}{2}\right)$ & $(1,2,3)$ & $(2,3,4)$ & $(1,2,3)$ \\
P-4 & $(5,6,7 ; 1)$ & $(1,2,3)$ & $(2,3,4)$ & $(1,1,1)$ & $(4,5,6)$ & $(5,6,7)$ & $(3,4,5)$ \\
P-5 & $(1,2,3 ; 1)$ & $\left(\frac{1}{4}, \frac{1}{3}, \frac{1}{2}\right)$ & $\left(\frac{1}{3}, \frac{1}{2}, \frac{1}{1}\right)$ & $\left(\frac{1}{6}, \frac{1}{5}, \frac{1}{4}\right)$ & $(1,1,1)$ & $(2,3,4)$ & $\left(\frac{1}{3}, \frac{1}{2}, \frac{1}{1}\right)$ \\
P-6 & $\left(\frac{1}{3}, \frac{1}{2}, \frac{1}{1}\right)$ & $\left(\frac{1}{4}, \frac{1}{3}, \frac{1}{2}\right)$ & $\left(\frac{1}{4}, \frac{1}{3}, \frac{1}{2}\right)$ & $\left(\frac{1}{7}, \frac{1}{6}, \frac{1}{5}\right)$ & $\left(\frac{1}{4}, \frac{1}{3}, \frac{1}{2}\right)$ & $(1,1,1)$ & $\left(\frac{1}{4}, \frac{1}{3}, \frac{1}{2}\right)$ \\
P-7 & $(1,2,3)$ & $\left(\frac{1}{3}, \frac{1}{2}, \frac{1}{1}\right)$ & $\left(\frac{1}{3}, \frac{1}{2}, \frac{1}{1}\right)$ & $\left(\frac{1}{5}, \frac{1}{4}, \frac{1}{3}\right)$ & $(1,2,3)$ & $(2,3,4)$ & $(1,1,1)$ \\
\hline
\end{tabular}

biomass is the lower level of the samples. During pyrolysis, ash particles usually extinguish the vapour conversion. So for this process, the biomass with reduced ash content is often preferred. As a result, the best material for pyrolysis should have most of volatile matter, fixed carbon, and lowest moisture and ash contents. Based on the above characteristic study, the properties such as cellulose, hemicellulose, volatile matter, and fixed carbon are considered as beneficial (high are better) and lignin, moisture, and ash contents are considered as nonbeneficial (low are better).

3.3. Ranking of the Material. The fuzzy pairwise comparison matrix for weight calculation using type-1 fuzzy AHP is shown in Table 1. The weights are derived using geometric mean method [44]. The type-1 fuzzy weights are defuzzified to obtain the crisp numeric weights, which are further normalised to obtain the final weights of criteria. These values are reproduced by multiplication with the evaluation matrix to get preference score. Table 2 displays the weighted normalised evaluation matrix. The graphical representations of the ranks are also shown in Figure 11. It can be seen that sugarcane bagasse is the best alternative having rank 1 . The
TABLE 2: Weighted normalised evaluation matrix.

\begin{tabular}{cccccccc}
\hline & P-1 & P-2 & P-3 & P-4 & P-5 & P-6 & P-7 \\
\hline M-1 & .0449 & .1255 & .0689 & .3577 & .0420 & .0251 & .0533 \\
M-2 & .0476 & .1892 & .0994 & .3337 & .0737 & .0431 & .0573 \\
M-3 & .0294 & .1857 & .0718 & .3586 & .0588 & .0419 & .1042 \\
M-4 & .0462 & .1446 & .0646 & .2662 & .0824 & .0094 & .0559 \\
M-5 & .0603 & .1525 & .1367 & .3631 & .0443 & .0279 & .0739 \\
M-6 & .0539 & .2052 & .0934 & .3549 & .0256 & .0118 & .0996 \\
M-7 & .0184 & .1083 & .0620 & .3043 & .0773 & .0137 & .1091 \\
\hline
\end{tabular}

next best material is hardwood which is ranked 2. The ranks are obtained based on the preference score shown in Table 3 , and Table 4 shows the ranks of the selected biomass materials based on the preference score. The lignin percentage of sugarcane bagasse is so low compared to other materials, and the lower lignin level of $13.4 \%$ and greater hemicellulosic content of $47.6 \%$ forecast the best option for optimum bio-oil production. The moisture level of the sugarcane bagasse is also quite low, at only $5.4 \mathrm{wt} \%$. As a result, sugarcane bagasse provides greater quality and has a higher 


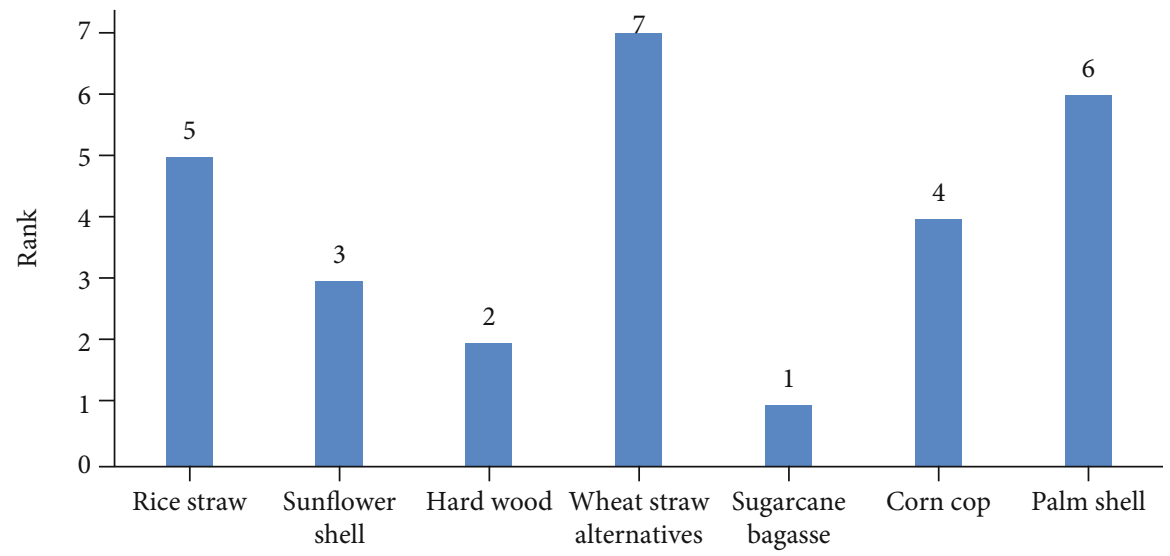

Figure 11: Rank of the biomass material.

Table 3: Preference score.

\begin{tabular}{lc}
\hline Alternatives & Preference score \\
\hline M-1 & 0.7156 \\
M-2 & 0.8433 \\
M-3 & 0.8492 \\
M-4 & 0.6690 \\
M-5 & 0.8577 \\
M-6 & 0.8429 \\
M-7 & 0.6923 \\
\hline
\end{tabular}

TABLE 4: Ranking of the material based on preference score.

\begin{tabular}{lc}
\hline Alternatives & Rank \\
\hline RS (M-1) & 5 \\
SS (M-2) & 3 \\
HW (M-3) & 2 \\
WS (M-4) & 7 \\
SB (M-5) & 1 \\
CC (M-6) & 4 \\
PS (M-7) & 6 \\
\hline
\end{tabular}

heating value. The quality of the oil is generally affected by the water content of the biomass feedstock [45]. Various researches have also confirmed this. One of the reasons for the superior quality of the bio-oil is the lower ash level of the sugarcane bagasse [46]. Wheat straw has higher moisture content than other biomass materials, as well as a lower cellulose content, which means it has a lesser chance of producing maximum bio-oil yield [47]. As a result, it was placed seventh among the other selected materials. During thermochemical conversion processes, there is a strong relation among the degradation of volatile contents and the rise in product yield [48]. The production of biofuels results in a $90 \%$ loss of their volatile constituents [49]. Even if rice straw and sugarcane bagasse have the same quantity of volatile matter, higher level of hemicellulose and lower ash content in sugarcane bagasse may be the key reason for its ranking among other biomass materials and for the prediction of acceptable biomass.
TABLE 5: Yield of biofuel under selected operating condition.

\begin{tabular}{|c|c|c|c|c|}
\hline \multirow[b]{2}{*}{ Feedstock } & \multirow[b]{2}{*}{$\begin{array}{c}\text { Fuzzy- } \\
\text { based rank }\end{array}$} & \multicolumn{2}{|c|}{ Bio-oil yield in wt\% } & \multirow[b]{2}{*}{$\begin{array}{l}\text { Experimental } \\
\text { rank }\end{array}$} \\
\hline & & $\begin{array}{l}\text { Thermal } \\
\text { pyrolysis }\end{array}$ & $\begin{array}{l}\text { Catalytic } \\
\text { pyrolysis }\end{array}$ & \\
\hline $\begin{array}{l}\text { Sugarcane } \\
\text { bagasse }\end{array}$ & 1 & 48.3 & 50.4 & 1 \\
\hline Hardwood & 2 & 44.6 & 46.8 & 2 \\
\hline
\end{tabular}

3.4. Experimental Validation. The yield of bio-oil with respect to biomass pyrolysis and catalytic pyrolysis is shown in Table 5. For thermal pyrolysis, the yield of bio-oil is $48.3 \mathrm{wt} \%$ for sugarcane bagasse and $44.6 \mathrm{wt} \%$ for hardwood material. At a catalyst loading of $2 \mathrm{wt} \%$, the bio-oil yield is increased to $50.4 \mathrm{wt} \%$ and $46.8 \mathrm{wt} \%$ for sugarcane pyrolysis and hardwood, respectively. The yield of bio-oil from topranked sugarcane bagasse via thermal pyrolysis and catalytic pyrolysis is more when compared to second-ranked hardwood. When the experimental and theoretical findings were compared, they were virtually identical, indicating a strong correlation between them.

\section{Conclusion}

In this study, type-1 fuzzy set approach was used to design a mechanism for selecting optimal biomass material for the pyrolysis process for maximum bio-oil yield. The type-1 fuzzy set was suggested which helps in the process of selecting suitable biomass materials among a large number of available alternatives. By considering seven evaluation criteria, this study gives the ranking order of the materials based on the performance score, and the order was sugarcane bagasse $>$ hardwood $>$ sunflower shell $>$ corn cop $>$ rice straw $>$ palm shell $>$ wheat straw. For a particular biomass material selection problem, this method considers biomass material selection qualities and their interrelationships. This method yields significant results and also establishes a link between previous studies for appropriate material selection for optimal bio-oil yield. The results of this method are in good accord with those of experiments. Under the same experimental circumstances, the top-ranked material yielded $3.7 \mathrm{wt} \%$ and $3.6 \mathrm{wt} \%$ more liquid oil than the second-ranked 
material during thermal and catalytic pyrolysis, respectively. The results provide confidence, and this approach can be applied for other thermochemical conversion processes in order to identify the best biomass material.

\section{Data Availability}

The data used to support the findings of this study are included in the article.

\section{Conflicts of Interest}

The authors declare that there is no conflict of interest regarding the publication of this article.

\section{Acknowledgments}

Alagar Karthick gratefully acknowledges group FQM-383 from Universidad de Cordoba, Spain, for the provision of an honorary visiting research position in the group. This project was funded by the Researchers Supporting Project number (RSP-2021/405), King Saud University, Riyadh, Saudi Arabia.

\section{References}

[1] P. V. Elumalai, M. Parthasarathy, J. S. Lalvani et al., "Effect of injection timing in reducing the harmful pollutants emitted from CI engine using N-butanol antioxidant blended ecofriendly Mahua biodiesel," Energy Reports, vol. 7, pp. 62056221, 2021.

[2] C. S. Dhanalakshmi and P. Madhu, "Recycling of wood bark of Azadirachta indica for bio-oil and chemicals by flash pyrolysis," Indian Journal of Ecology, vol. 46, no. 2, pp. 347-353, 2019.

[3] T. Werpy and G. Petersen, "Top value added chemicals from biomass NATO," Advanced Science Institute, vol. 1, no. 2, pp. 263-275, 2004.

[4] B. Agarwal, K. Kailasam, R. S. Sangwan, and S. Elumalai, "Traversing the history of solid catalysts for heterogeneous synthesis of 5-hydroxymethylfurfural from carbohydrate sugars: a review," Renewable and Sustainable Energy Reviews, vol. 82, pp. 2408-2425, 2018.

[5] P. Madhu, H. Kanagasabapathy, and I. N. Manickam, "Conversion of cotton residues to bio-oil and chemicals through flash pyrolysis in a fluidised bed reactor," International Journal of Energy Technology and Policy, vol. 14, no. 1, pp. 20-33, 2018.

[6] X. Li, P. Jia, and T. Wang, "Furfural: a promising platform compound for sustainable production of C4and C5Chemicals," ACS Catalysis, vol. 6, no. 11, pp. 7621-7640, 2016.

[7] A. H. Lee, H. Y. Kang, C. F. Hsu, and H. C. Hung, "A green supplier selection model for high-tech industry," Expert Systems with Applications, vol. 36, no. 4, pp. 7917-7927, 2009.

[8] D. Dubois and H. Prade, Fundamentals of fuzzy sets (Vol. 7), Springer Science \& Business Media, 2012.

[9] G. Büyüközkan, "An integrated fuzzy multi-criteria group decision-making approach for green supplier evaluation," International Journal of Production Research, vol. 50, no. 11, pp. 2892-2909, 2012.

[10] L. A. Zadeh, "Fuzzy sets," Information And Control, vol. 8, no. 3, pp. 338-353, 1965.
[11] V. N. Salii, "Relations Izv. Vysh. Uchebn. Zaved," Matematika, vol. 44, no. 1, pp. 133-145, 1965.

[12] M. Kilic and İ. Kaya, "Investment project evaluation by a decision making methodology based on type-2 fuzzy sets," Applied Soft Computing, vol. 27, pp. 399-410, 2015.

[13] A. Chehri and H. T. Mouftah, "FEMAN: Fuzzy-based energy management system for green houses using hybrid grid solar power," Journal of Renewable Energy, vol. 2013, Article ID 785636, 6 pages, 2013.

[14] J. S. GK, "MANFIS based SMART home energy management system to support SMART grid," Peer-to-Peer Networking \& Applications, vol. 13, no. 6, 2020.

[15] F. Chekired, A. Mahrane, Z. Samara, M. Chikh, A. Guenounou, and A. Meflah, "Fuzzy logic energy management for a photovoltaic solar home," Energy Procedia, vol. 134, pp. 723-730, 2017.

[16] V. J. Manoj Praveen, R. Vigneshkumar, N. Karthikeyan, A. Gurumoorthi, R. Vijayakumar, and P. Madhu, "Heat transfer enhancement of air-concrete thermal energy storage system-CFD simulation and experimental validation under transient condition," Proceedings of the Institution of Mechanical Engineers, Part E: Journal of Process Mechanical Engineering, no. article 09544089211007370, 2021.

[17] C. T. Chen, "A fuzzy approach to select the location of the distribution center," Fuzzy Sets and Systems, vol. 118, no. 1, pp. 65-73, 2001.

[18] L. Todorova, K. Atanassov, S. Hadjitodorov, and P. Vassilev, "On an intuitionistic fuzzy approach for decision making in medicine: part 2," International Journal Bioautomation, vol. 7, pp. 64-69, 2007.

[19] R. Liao, H. Zheng, S. Grzybowski, L. Yang, Y. Zhang, and Y. Liao, "An integrated decision-making model for condition assessment of power transformers using fuzzy approach and evidential reasoning," IEEE Transactions on Power Delivery, vol. 26, no. 2, pp. 1111-1118, 2011.

[20] I. Ahmed, I. Sultana, S. K. Paul, and A. Azeem, "Employee performance evaluation: a fuzzy approach," International Journal of Productivity and Performance Management, vol. 62, no. 7, pp. 718-734, 2013.

[21] M. Amiri, M. Hashemi-Tabatabaei, M. Ghahremanloo, M. Keshavarz-Ghorabaee, E. K. Zavadskas, and J. Antucheviciene, "A new fuzzy approach based on BWM and fuzzy preference programming for hospital performance evaluation: a case study," Applied Soft Computing, vol. 92, article 106279, 2020.

[22] W. A. Rasaq, M. Golonka, M. Scholz, and A. Białowiec, "Opportunities and challenges of high-pressure fast pyrolysis of biomass: a review," Energies, vol. 14, no. 17, p. 5426, 2021.

[23] A. A. Lappas, K. G. Kalogiannis, E. F. Iliopoulou, K. S. Triantafyllidis, and S. D. Stefanidis, "Catalytic pyrolysis of biomass for transportation fuels," Wiley Interdisciplinary Reviews: Energy and Environment, vol. 1, no. 3, pp. 285-297, 2012.

[24] D. Pan, F. Su, H. Liu et al., "Research progress on catalytic pyrolysis and reuse of waste plastics and petroleum sludge," ES Materials \& Manufacturing, vol. 11, no. 2, pp. 3-15, 2021.

[25] M. Hu, B. Cui, B. Xiao, S. Luo, and D. Guo, "Insight into the ex situ catalytic pyrolysis of biomass over char supported metals catalyst: syngas production and tar decomposition," Nanomaterials, vol. 10, no. 7, p. 1397, 2020.

[26] J. Chen, C. Liu, S. Wu, J. Liang, and M. Lei, "Enhancing the quality of bio-oil from catalytic pyrolysis of kraft black liquor 
lignin,” RSC Advances, vol. 6, no. 109, pp. 107970-107976, 2016.

[27] M. Jafarian and S. E. Vahdat, "A fuzzy multi-attribute approach to select the welding process at high pressure vessel manufacturing," Journal of Manufacturing Processes, vol. 14, no. 3, pp. 250-256, 2012.

[28] H. Kahr, J. Wimberger, D. Schürz, and A. Jäger, "Evaluation of the biomass potential for the production of lignocellulosic bioethanol from various agricultural residues in Austria and worldwide," Energy Procedia, vol. 40, pp. 146-155, 2013.

[29] A. Ciancolini, M. Alignan, M. A. Pagnotta, G. Vilarem, and P. Crinò, "Selection of Italian cardoon genotypes as industrial crop for biomass and polyphenol production," Industrial Crops and Products, vol. 51, pp. 145-151, 2013.

[30] M. Vaezi, M. Passandideh-Fard, M. Moghiman, and M. Charmchi, "On a methodology for selecting biomass materials for gasification purposes," Fuel Processing Technology, vol. 98, pp. 74-81, 2012.

[31] P. H. Schipper, F. G. Dwyer, P. T. Sparrell, S. Mizrahi, and J. A. Herbst, "Zeolite ZSM-5 in Fluid Catalytic Cracking: Performance, Benefits, and Applications," in ACS Symposium Series, pp. 64-86, ACS Publications, Washington, DC, 1988.

[32] P. Hemberger, V. B. Custodis, A. Bodi, T. Gerber, and J. A. van Bokhoven, "Understanding the mechanism of catalytic fast pyrolysis by unveiling reactive intermediates in heterogeneous catalysis," Nature Communications, vol. 8, no. 1, pp. 1-9, 2017.

[33] K. Senthilnathan, G. Suresh, S. Ilaiyavel, R. Ravi, and S. Srinivasan, "Experimental investigation of polymer matrix composites gears with different fiber proportions," International Journal of Vehicle Structures and Systems, vol. 12, no. 2, pp. 212-216, 2020.

[34] L. A. Costa, A. F. Fonseca, F. V. Pereira, and J. I. Druzian, "Extraction and characterization of cellulose nanocrystals from corn stover," Cellulose Chemistry and Technology, vol. 49, no. 2, pp. 127-133, 2015.

[35] Q. Yang and X. Pan, "Correlation between lignin physicochemical properties and inhibition to enzymatic hydrolysis of cellulose," Biotechnology and Bioengineering, vol. 113, no. 6, pp. 1213-1224, 2016.

[36] L. Ye, Y. Han, J. Feng, and X. Lu, “A review about GVL production from lignocellulose: focusing on the full components utilization," Industrial Crops and Products, vol. 144, article 112031, 2020.

[37] M. Hajaligol, B. Waymack, and D. Kellogg, "Low temperature formation of aromatic hydrocarbon from pyrolysis of cellulosic materials," Fuel, vol. 80, no. 12, pp. 1799-1807, 2001.

[38] X. Jin, X. Chen, C. Shi et al., "Determination of hemicellulose, cellulose and lignin content using visible and near infrared spectroscopy in Miscanthus sinensis," Bioresource Technology, vol. 241, pp. 603-609, 2017.

[39] A. Gani and I. Naruse, "Effect of cellulose and lignin content on pyrolysis and combustion characteristics for several types of biomass," Renewable Energy, vol. 32, no. 4, pp. 649-661, 2007.

[40] C. S. Dhanalakshmi, P. Madhu, A. Karthick, M. Mathew, and R. V. Kumar, "A comprehensive MCDM-based approach using TOPSIS and EDAS as an auxiliary tool for pyrolysis material selection and its application," Biomass Conversion and Biorefinery, pp. 1-16, 2020.

[41] S. Xiong, J. Zhuo, B. Zhang, and Q. Yao, "Effect of moisture content on the characterization of products from the pyrolysis of sewage sludge," Journal of Analytical and Applied Pyrolysis, vol. 104, pp. 632-639, 2013.

[42] K. Sudalaiyandi, K. Alagar, V. J. MP, and P. Madhu, "Performance and emission characteristics of diesel engine fueled with ternary blends of linseed and rubber seed oil biodiesel," Fuel, vol. 285, article 119255, 2021.

[43] R. Samuelsson, S. H. Larsson, M. Thyrel, and T. A. Lestander, "Moisture content and storage time influence the binding mechanisms in biofuel wood pellets," Applied Energy, vol. 99, pp. 109-115, 2012.

[44] N. Y. Pehlivan, T. Paksoy, and A. Çalik, "Comparison of Methods in FAHP with Application in Supplier Selection," in Fuzzy Analytic Hierarchy Process, pp. 67-98, Chapman and Hall/CRC, 2017.

[45] D. Carpenter, T. L. Westover, S. Czernik, and W. Jablonski, "Biomass feedstocks for renewable fuel production: a review of the impacts of feedstock and pretreatment on the yield and product distribution of fast pyrolysis bio-oils and vapors," Green Chemistry, vol. 16, no. 2, pp. 384-406, 2014.

[46] J. Zhang, J. Liu, and R. Liu, "Effects of pyrolysis temperature and heating time on biochar obtained from the pyrolysis of straw and lignosulfonate," Bioresource Technology, vol. 176, pp. 288-291, 2015.

[47] I. Petric, A. Šestan, and I. Šestan, "Influence of initial moisture content on the composting of poultry manure with wheat straw," Biosystems Engineering, vol. 104, no. 1, pp. 125-134, 2009.

[48] V. Balasundram, N. Ibrahim, R. M. Kasmani et al., “Thermogravimetric catalytic pyrolysis and kinetic studies of coconut copra and rice husk for possible maximum production of pyrolysis oil," Journal of Cleaner Production, vol. 167, pp. 218-228, 2017.

[49] Y. C. Chen and L. Y. Chen, "Pelleting spent coffee grounds by waste utensils as binders of biofuels," Journal of Environmental Chemical Engineering, vol. 9, no. 3, article 105006, 2021. 